\title{
Sistem Cerdas untuk Inovasi Blender Control System Menggunakan Fuzzy Control System dengan Metode Mamdani
}

\author{
Khomarudin Fahuzan ${ }^{1}$, Uke Ralmugiz ${ }^{2}$
}

1) Universitas Negeri Yogyakarta, Indonesia

2) Universitas Muhammadiyah Kupang, Indonesia

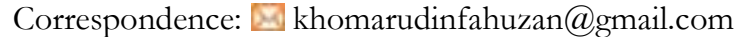

\begin{tabular}{|c|c|}
\hline Article Info & \multirow{8}{*}{$\begin{array}{l}\text { Abstract } \\
\text { This research aims to establish a control system on blender by using fuzzy } \\
\text { control system with mamdani method. In this study, researchers used input in } \\
\text { the form of hardness level and volume of fruit to be blend, while the output is } \\
\text { blend time ( } 0 \text { to } 180 \text { seconds) with assumption of constant blender velocity). } \\
\text { Researchers used fuzzy inference control system with Mamdani method with } \\
\text { some stages: fuzzification, inference, rule base, and defuzzification. Fuzzification } \\
\text { changes the hardness of the fruit and the volume into a value. Inference created } \\
\text { fuzzy output using pre-made rules. Defuzzification counted the time it takes to } \\
\text { blend into output. Based on the results of the research, the results obtained for } \\
\text { the sample of fruit with a level of hardness of } 40 \% \text {, and volume } 4 \text { ( } 400 \text { ml), in } \\
\text { obtaining the minimum time required to smooth the fruit about } 79 \text { seconds. } \\
\text { Thus the fuzzy control system can be used as an innovation to make the control } \\
\text { system in blender. This system not only applies to blenders only, but also can be } \\
\text { applied to other machines using fuzzy control system }\end{array}$} \\
\hline Article History & \\
\hline Received : 13-03-2018 & \\
\hline Revised & \\
\hline Accepted : 19-09-2018 & \\
\hline Keywords: & \\
\hline & \\
\hline & \\
\hline
\end{tabular}

\section{PENDAHULUAN}

Teknologi berkembang pesat. Perkembangan teknologi di segala aspek kehidupan. Teknologi semakin dibuat lebih efektif dan efisien. Sistem komputer menjadi industri yang berkembang paling cepat di U.S. [1]. Teknologi yang berkembang paling pesat diantaranya adalah dalam bidang buah-sayur (21\%), daging (21\%), dan jus/minuman (20\%) [2]. Bidang peralatan dapur menunjukkan angka pertumbungan yang terus meningkat [3]. Artinya, perkembangan teknologi dalam peralatan dapur saat ini menunjukkan bahwa manusia semakin menyukai hal-hal yang lebih otomatis dan efisien.

Di sisi lain, pesatnya perkembangan teknologi sejalan dengan meningkatnya kesadaran manusia untuk menjalani pola hidup sehat, salah satunya dengan meningkatnya konsumsi buah-buahan saat ini [4]. Salah satu cara konsumsi buah-buahan yang favorit selain dimakan langsung adalah dengan membuatnya menjadi jus. Hal ini terlihat juga terlihat dari meningkatnya peminat blender dari seluruh dunia [5]. Blender adalah alat yang digunakan untuk melumatkan benda yang dimasukkan yang ada di dalamnya, tentu dengan kriteria-kriteria tertentu. Mesin blender pada awalnya dikembangkan oleh pada tahun 1937 yang merupakan pengembangan dari mesin mixer yang berkembang dari tahun 1810 dan terus berkembang hingga saat ini [6]. Kemudian dikembangkan menjadi sampai dengan saat ini yang lebih menekankan pada kapasitas blender dan mesin yang semakin kuat [7]. Tetapi, blender yang berkembang saat ini masih menggunakan kontrol manual. Di pasaran pun juga masih banyak yang menggunakan kontrol manual.

Pengguna masih perlu menentukan waktu yang diperlukan untuk menghaluskan. Selain itu, buah memiliki karakteristik yang berbeda-beda, buah yang lunak akan lebih mudah diblender daripada buah yang keras seperti kelapa, volume buah yang akan diblender pun juga mempengaruhi waktu kerja blender [8]. Jadi, waktu yang diperlukan untuk memblender berbeda-beda. Oleh karena itu, akan lebih 
efisien jika ada suatu kontrol yang mengatur waktu yang dibutuhkan untuk memblender buah dengan otomatis tanpa perlu mengamati dengan seksama, yaitu dengan menggunakan furay system control. Jika waktu yang digunakan untuk memblender dapat efisien, maka akan didapatkan hasil yang bagus, dan konsumsi listrik dapat dihemat, terutama untuk produsen jus karena daya blender bisa mencapai 700 watt.

Sebenarnya gagasan semacam ini sudah ada sebelumnya, yaitu rancangan sistem kontrol mixer untuk mencampur warna [9]. Rancangan sistem kontrol pada mesin mixer, dengan memperhatikan volume, viskositas, dan pemilihan produk [10]. Selanjutnya, penelitian tentang sistem kontrol untuk mencampurkan sirup secara otomatis agar didapat hasil yang lebih efisien [11]. Rancangan sistem kontrol pada penggiling yang mempertimbangkan volume dan jenis material yang akan digiling [12]. Peneliti merasa ada kemiripan penerapan furay control system pada penelitian yang sudah ada yang dapat digunakan sebagai bahan rujukan untuk merancang sistem kontrol pada mesin blender ini.

Penelitian ini bertujuan untuk merancang sistem kontrol pada blender dengan menggunakan fuz:y control system dengan metode mamdani. Dalam penelitian ini, peneliti menggunakan kecepatan rata-rata blender, dan diperkirakan waktu memblender buah sekitar 0 sampai 180 detik (3 menit). Hasil dari penelitian ini adalah rancangan sistem kontrol yang nantinya akan menghasilkan waktu minimal yang dibutuhkan untuk memblender berbagai macam buah yang berbeda-beda dengan mempertimbangkan tingkat kekerasan buah dan volumenya.

\section{METODE PENELITIAN}

Peneliti menggunakan sistem inferensi furay dengan Metode Mamdani, yang akan dijelasakan sebagai berikut;

\section{A. Logika Furay}

Logika mempelajari metode dan prinsip dasar pengambilan keputusan, yang berarti proposisi yang baru dari proposisi yang telah ada. Dalam logika klasik, sebuah proporsi hanya memiliki dua nilai, yakni niali benar atau salah, tidak ada nilai yang sedang. Dalam logika fuz:y y, nilai suatu proporsi bukan hanya benar dan dan salah, namun juga ada nilai diantara keduanya. Nilai kebenarannya bukan hanya 0 dan 1, tetapi juga nilai-nilai diantaranya. Prinsip logika fur:y banyak digunakan diberbagai bidang, bidang kedokteran untuk diagnosa penyakit, peramalan cuaca, mesin cuci otomatis, dan banyak lainnya. Logika Fuгzy pertama kali dikembangkan oleh Lotfi A. Zadeh tahun 1965 [13].

\section{B. Operator Fuzay Control System}

Operator dasar pada sistem Furay Control menurut Zadeh untuk Operasi Himpunan Fuzzy memiliki tiga operator dasar sebagai berikut :

1. Operator $A N D$, operasi dengan operator $A N D$ diperoleh dengan mengambil nilai keanggotaan terkecil antara elemen pada himpunan-himpunan yang bersangkutan.

2. Operator $O R$, operasi dengan operator $O R$ diperoleh dengan mengambil nilai keanggotaan terbesar antara elemen pada himpunan-himpunan yang bersangkutan.

3. Operator NOT, operasi dengan operator NOT diperoleh dengan mengurangkan nilai keanggotaan elemen pada anggota himpunan dengan 1 [13].

Secara umum, ada 2 fungsi implikasi fuzay control yang dapat digunakan, sebagai berikut :

1. Min (minimum). Fungsi ini akan memotong output himpunan furzy.

2. Dot (product). Fungsi ini akan menskala output himpunan fursy [13]

3. Furay Control System 
Metode Mamdani sering juga dikenal dengan nama Metode Max-Min. Metode ini diperkenalkan oleh Ebrahim Mamdani pada tahun 1975. Untuk mendapatkan output, diperlukan 4 tahapan:

1. Pembentukan Himpunan Fuzzy

2. Aplikasi fungsi implikasi (aturan)

3. Komposisi aturan

4. Penegasan (defuzzyfikasi) [14]

Gambar 1 menunjukkan skema furgy control yang akan kita gunakan. Terdapat tiga tahapan dalam furay control di atas, yakni fuzzifikasi, inferensi, basis aturan dan defuzzifikasi. Fuzzifikasi merubah tingkat kekerasan buah, dan volume kedalam suatu nilai. Inferensi membuat output fuz:y menggunakan aturan yang telah dibuat sebelumnya. Defuzzifikasi menghitung banyak waktu yang dibutuhkan untuk memblender menjadi output.

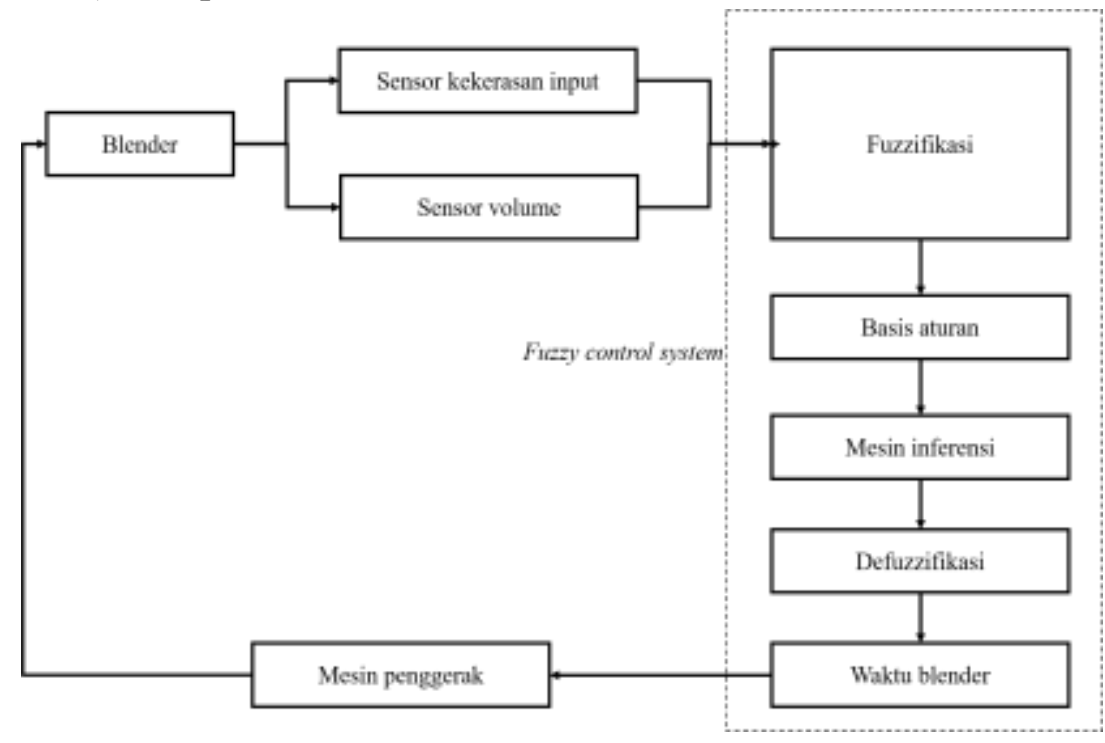

Gambar 1. Skema Fužy Control System untuk mesin blender

\section{HASIL DAN PEMBAHASAN}

Dalam penelitian ini, Furzy Control Metode Mamdani digunakan untuk mengontrol waktu kerja blender. Waktu kerja blender dipengaruhi oleh tingkat kekerasan buah dan volume yang terekam oleh sensor. Logika furay digunakan dalam penelitian ini karena kita dapat menentukan imput dan output kita secara relatif. Kita dapat mengatur input dan output sesuai dengan keinginan kita dengan cara merubah fungsi keanggotaannya.

Variabel input yang digunakan adalah tingkat kekerasan buah (\%), dan volume (per $100 \mathrm{ml}$ ). Output yang dihasilkan adalah waktu kerja blender (detik). Berikut kita akan mendefinisikan fungsi keanggotaan untuk masing-masing input dan output.

1. Input

a. Tingkat kekerasan buah

Terdapat tiga himpunan furay, yaitu rendah $\left(L_{d}\right)$, sedang $\left(M_{d}\right)$, dan tinggi $\left(H_{d}\right)$.

$$
L_{d}(x)=\left\{\begin{array}{cc}
1, \quad 0 \leq x \leq 20 \\
-\frac{1}{20} x+2,20 \leq x \leq 40 \\
0, \quad \text { lainnya }
\end{array}\right.
$$


Numerical: Jurnal Matematika dan Pendidikan Matematika, Vol. 2 No. 2 Desember 2018, 115-124 Khomarudin Fahuzan, Uke Ralmugiz

$$
\begin{aligned}
& M_{d}(x)=\left\{\begin{array}{cc}
\frac{1}{20} x-1, & 20 \leq x \leq 40 \\
1, & 40 \leq x \leq 60 \\
-\frac{1}{20} x+4, & 60 \leq x \leq 80 \\
0, & \text { lainnya }
\end{array}\right. \\
& H_{d}(x)=\left\{\begin{array}{cc}
\frac{1}{20} x-3, \quad & 60 \leq x \leq 80 \\
1, \quad & 80 \leq x \leq 100 \\
0, & \text { lainnya }
\end{array}\right.
\end{aligned}
$$

Grafik fungsi keanggotaan furæy dari tingkat kekerasan buah disajikan pada Gambar 2.

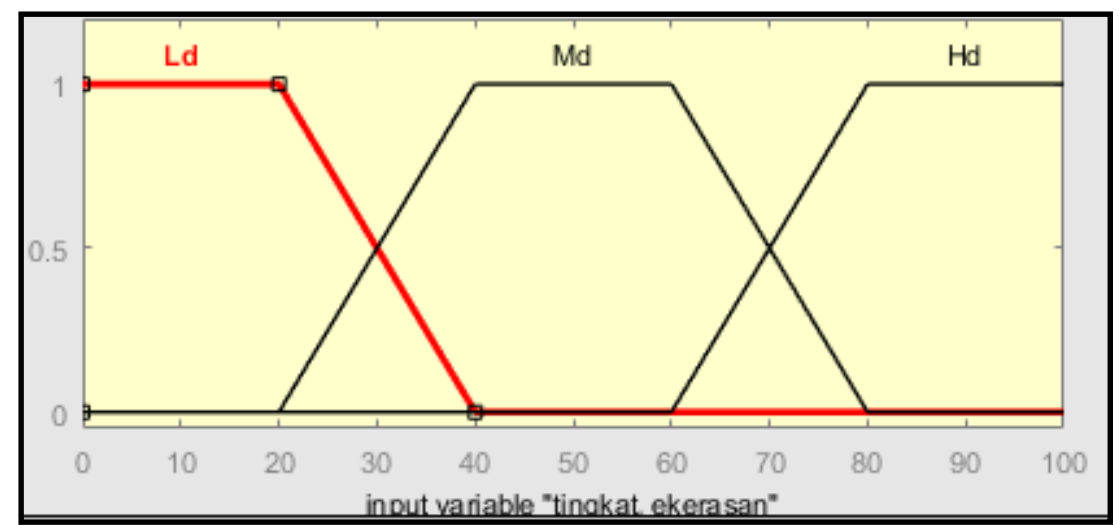

Gambar 2. Fungsi keanggotaan tingkat kekerasan buah

b. Volume

Terdapat tiga himpunan furay, yaitu sedikit $\left(S_{S}\right)$, medium $\left(M_{S}\right)$, dan banyak $\left(B_{S}\right)$.

$$
\begin{gathered}
S_{S}(x)=\left\{\begin{array}{cc}
-\frac{1}{5} x+1, & 0 \leq x \leq 5 \\
0, & \text { lainnya }
\end{array}\right. \\
M_{S}(x)=\left\{\begin{array}{cc}
\frac{1}{5} x, & 0 \leq x \leq 5 \\
-\frac{1}{5} x+2, & 5 \leq x \leq 10
\end{array}\right. \\
B_{S}(x)=\left\{\begin{array}{cc}
\frac{1}{5} x-1, & 5 \leq x \leq 10 \\
0, & \text { lainnya }
\end{array}\right.
\end{gathered}
$$

Grafik fungsi keanggotaan fuгæy dari volume disajikan pada Gambar 3.

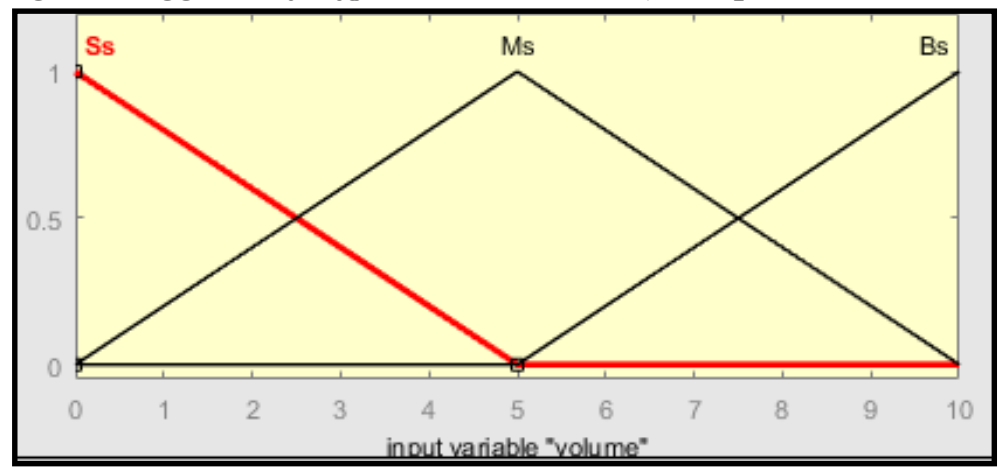

Gambar 3. Fungsi keanggotaan volume

\section{Output}


Waktu yang dibutuhkan blender, terdapat lima himpunan furzy, yaitu sangat singkat $\left(V S_{t}\right)$, singkat $\left(S_{t}\right)$, medium $\left(M_{t}\right)$, lama $\left(L_{t}\right)$, dan sangat lama $\left(V L_{t}\right)$.

$$
\begin{gathered}
V S_{t}(x)=\left\{\begin{array}{cc}
-\frac{1}{45} x+1, & 0 \leq x \leq 45 \\
0, & \text { lainnya }
\end{array}\right. \\
S_{t}(x)=\left\{\begin{array}{cc}
\frac{1}{45} x, & 0 \leq x \leq 45 \\
-\frac{1}{45} x+2, & 45 \leq x \leq 90 \\
0, & \text { lainnya }
\end{array}\right. \\
M_{t}(x)=\left\{\begin{array}{cc}
\frac{1}{45} x-1, & 45 \leq x \leq 90 \\
-\frac{1}{45} x+3, & 90 \leq x \leq 135 \\
0, & \text { lainnya }
\end{array}\right. \\
L_{t}(x)=\left\{\begin{array}{rr}
\frac{1}{45} x-2, & 90 \leq x \leq 135 \\
-\frac{1}{45} x+4, & 135 \leq x \leq 180 \\
0, & \text { lainnya }
\end{array}\right. \\
V L_{t}(x)=\left\{\begin{array}{cc}
\frac{1}{45} x-3, & 135 \leq x \leq 180 \\
0, & \text { lainnya }
\end{array}\right.
\end{gathered}
$$

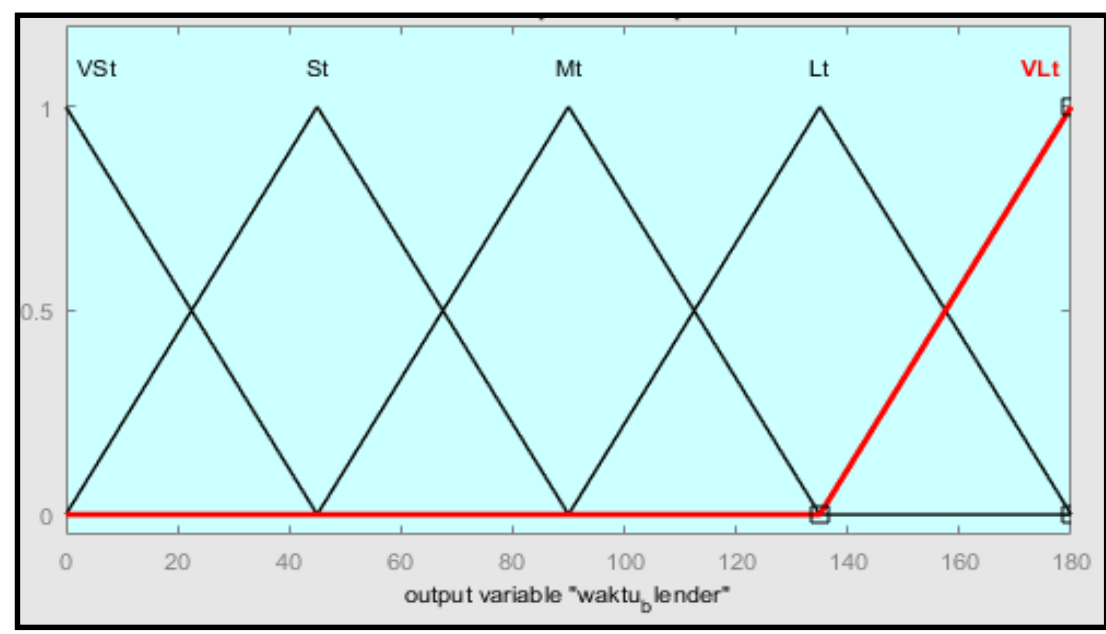

Gambar 4. Fungsi keanggotaan waktu kerja blender

Langkah selanjutnya adalah mendefinisikan aturan yang akan digunakan. Aturan-aturan tersebut dibuat sesuai dengan kebiasaan dan logika yang kita gunakan sehari-hari. Dalam penelitian ini menggunakan input masing-masing tiga pilihan keadaan, sehingga ada sembilan kemungkinan pasangan berurutan. Sembilan kemungkinan yang ada dapat disajikan dalam Gambar 5. Sembilan aturan ini merupakan aturan-aturan yang dijalankan dalam pengontrol samar. 


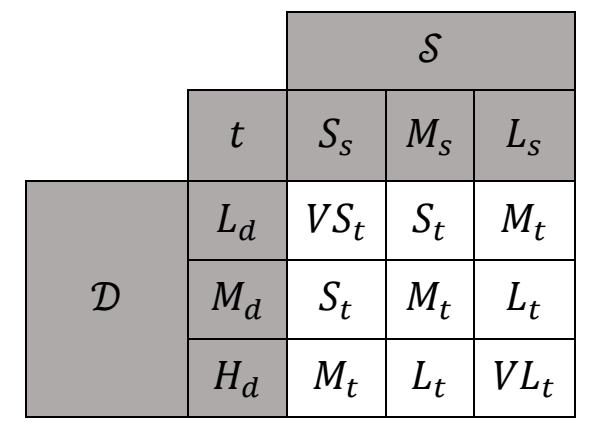

Gambar 5. Aturan inferensi untuk mesin blender

Rule tersebut dapat dijabarkan sebagai berikut:

1. If (tingkat kekerasan is Ld) and (volume is Ss) then (waktu blender is VSt) (1)

2. If (tingkat kekerasan is Ld) and (volume is Ms) then (waktu blender is St) (1)

3. If (tingkat kekerasan is $\mathrm{Ld}$ ) and (volume is Bs) then (waktu blender is Mt) (1)

4. If (tingkat kekerasan is $\mathrm{Md}$ ) and (volume is $\mathrm{Ss}$ ) then (waktu blender is St) (1)

5. If (tingkat kekerasan is $\mathrm{Md}$ ) and (volume is Ms) then (waktu blender is Mt) (1)

6. If (tingkat kekerasan is Md) and (volume is Bs) then (waktu blender is Lt) (1)

7. If (tingkat kekerasan is $\mathrm{Hd}$ ) and (volume is Ss) then (waktu blender is Mt) (1)

8. If (tingkat kekerasan is $\mathrm{Hd}$ ) and (volume is Ms) then (waktu blender is Lt) (1)

9. If (tingkat kekerasan is Hd) and (volume is Bs) then (waktu blender is VLt) (1)

Misal akan dimasukkan buah manga, alat sensor kekerasan dan volume akan mendeteksi tingkat kekerasan serta volume dari buah yang akan diblender. Misalnya tingkat kekerasan buah manga tersebut 40\% yang termasuk dalam kategori Sedang dan volumenya 4 (400ml) dalam kategori Medium. Kemudian proses selanjutnya adalah masuk dalam mesin inferensi furzy dengan aturan yang telah diukur sebelumnya.

Secara manual didapatkan fungsi berikut.

$$
\begin{aligned}
\int_{0}^{135} C_{\hat{d}, \hat{s}}(t) d x & \\
& =\int_{0}^{9}\left(\frac{1}{45} x\right) d x+\int_{9}^{54}(0.2) d x+\int_{54}^{81}\left(\frac{1}{45} x-1\right) d x+\int_{81}^{99}(0.8) d x \\
& +\int_{99}^{135}\left(-\frac{1}{45} x+3\right) d x
\end{aligned}
$$

Selanjutnya masuk dalam proses defuzzification, hasilnya adalah simpulan umum berupa waktu kerja blender dalam bilangan real. Dalam penelitian ini menggunakan metode mamdani dan dalam proses defurzification menggunakan centroid.

$$
t=\frac{\int_{0}^{135} x C_{\hat{d}, \hat{s}}(t) d x}{\int_{0}^{135} C_{\hat{d}, \hat{s}}(t) d x}
$$

Didapatkan

$$
\int_{0}^{135} x C_{\hat{d}, \hat{s}}(t) d x=4408.2
$$

dan

$$
\int_{10}^{40} C_{\widehat{d}, \hat{s}}(t) d x=55,8
$$


Numerical: Jurnal Matematika dan Pendidikan Matematika, Vol. 2 No. 2 Desember 2018, 115-124 Khomarudin Fahuzan, Uke Ralmugiz

Jadi,

$$
\begin{gathered}
\hat{t}=\frac{4408.2}{55.8} \\
\hat{t}=79 \text { detik }
\end{gathered}
$$

Dengan cara manual, didapatkan output waktu yang diperlukan untuk melumat buah mangga tersebut adalah 79 detik.

Selanjutnya akan dibandingkan dengan hasil perhitungan dengan menggunakan Matlab. Didapatkan hasil seperti pada Gambar 6.

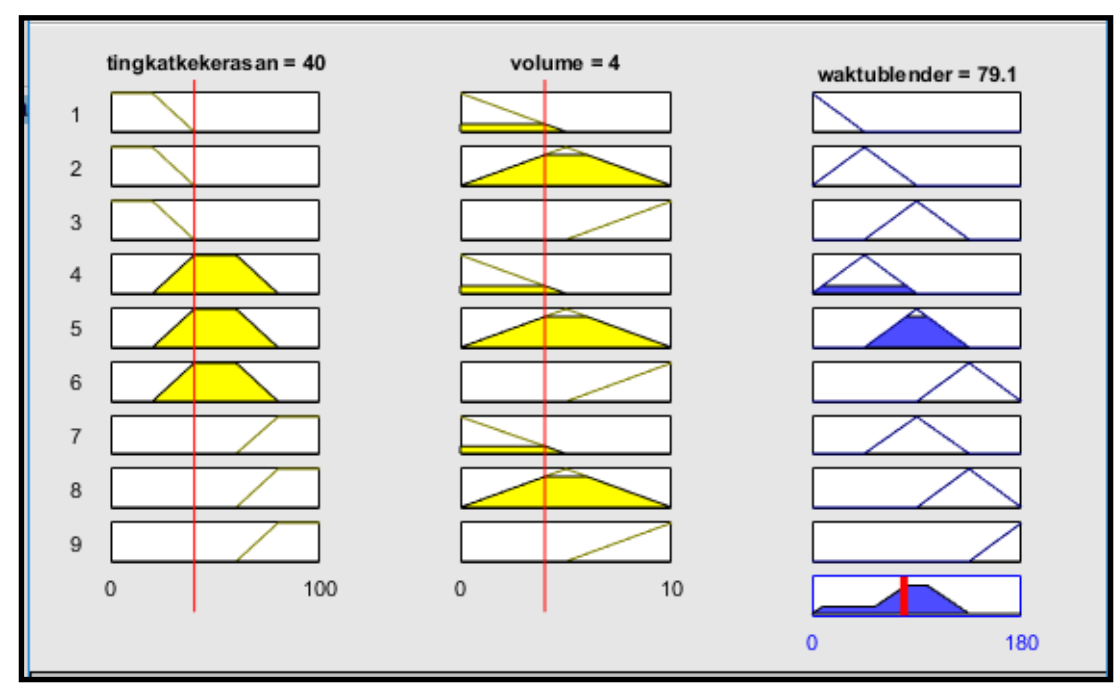

Gambar 6. Aturan furzy control

Peta waktu kerja blender berdasarkan input diatas dilihat pada Gambar 7.

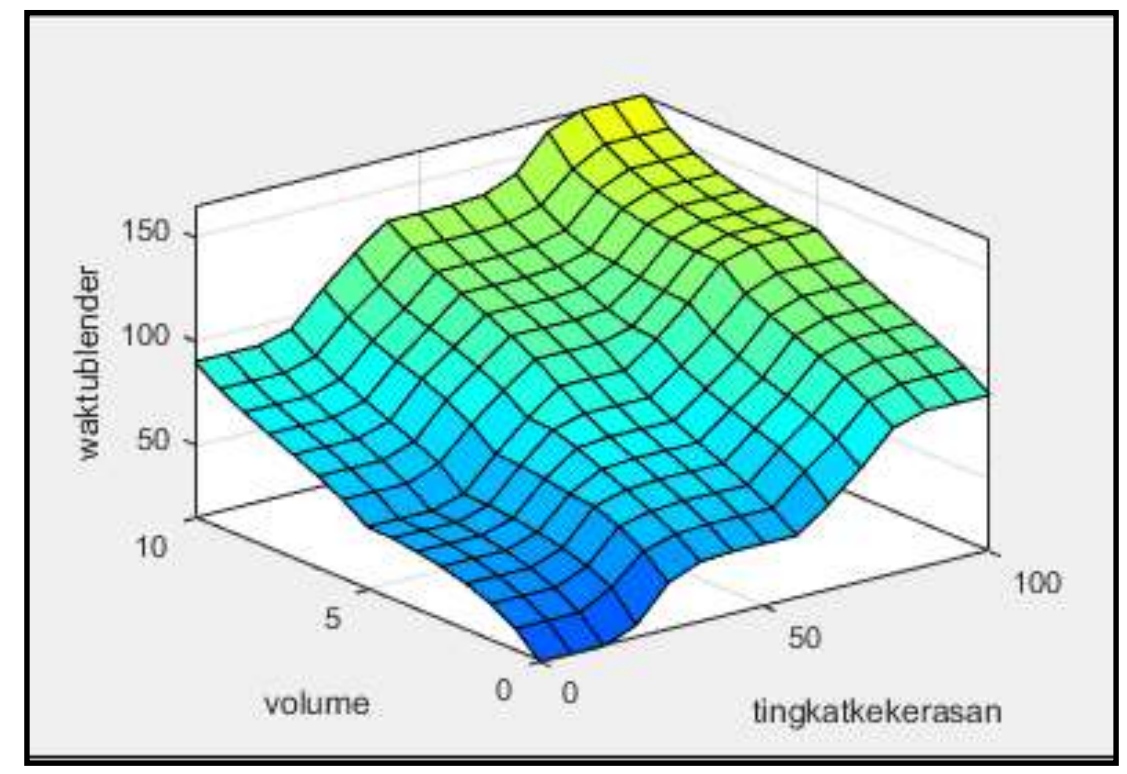

Gambar 7. Output peta waktu kerja blender

Berdasarkan contoh imput di atas, baik dari proses perhitungan manual maupun dengan menggunakan Matlab, diperoleh bahwa dengan tingkat kekerasan buah sebesar 40\%, dan volume 4 (400 $\mathrm{ml})$, sama-sama di peroleh waktu minimal yang dibutuhkan untuk menghaluskan buah mangga tersebut sekitar 79 detik. 


\section{SIMPULAN DAN SARAN}

Berdasarkan hasil penelitian diperoleh data bahwa fuzzy control system dapat digunakan sebagai suatu inovasi membuat sistem kontrol pada blender. Sebagai contoh buah dengan tingkat kekerasan sebesar 40\%, dan volume $4(400 \mathrm{ml})$, di peroleh waktu minimal yang dibutuhkan untuk menghaluskan buah tersebut sekitar 79 detik.

Perencanaan sistem kontrol blender otomatis sangatlah berguna untuk memenuhi kebutuhan masyarakat. Untuk penelitian selanjutnya, dapat ditambahkan berbagai variabel kontrol lain yaitu tingkat kecepatan putaran mesin blender, sehingga waktu outputnya dapat disesuaikan lagi, karena dalam penelitian ini hanya menggunakan kecepatan yang konstan saja, sehingga outputnya hanya diperkirakan sekitar 0 sampai 180 detik. Sebenarnya penelitian ini tidak hanya berlaku pada buah saja, tetapi dapat digunakan untuk jenis yang lainnya asalkan memenuhi kriteria-kriteria tertentu seperti dapat dilumatkan. Jadi, diharapkan hasil penelitian ini dapat dimanfaatkan untuk penyusunan mesin blender agar dapat dirasakan manfaatnya oleh masyarakat.

\section{DAFTAR PUSTAKA}

[1] M. E. Biery, “The 10 Fastest-Growing Industries In The U.S.," Sageworks Stats, 2017. [Online]. Available: https://www.forbes.com/sites/sageworks/2017/04/09/the-10-fastest-growingindustries-in-the-u-s/\#7f1b2d531ef2. [Accessed: 01-Nov-2018].

[2] D. Berry, "High pressure processing providers and users partnering to promote technology," Food Safety News, 2017. [Online].

Available:http://www.foodbusinessnews.net/articles/news_home/Food_Safety_News/2017/04/

High_pressure_processing_provi.aspx?ID=\%7B6D1B6170-CA11-412B-8F3B-

3C2DD9646205\%7D\&cck=1. [Accessed: 01-Nov-2018].

[3] G. V. Research, "Food Service Equipment Market Analysis By Product (Kitchen Purpose, Refrigeration, Storage, Ware Washing, Food Holding And Serving), By Washware Equipment (Booster Heaters, Dish Washers, Disposers, Utensil Washer) And Segment Forecasts To 2024," California, 2016.

[4] HegiLibrary, "Fruit Consumption Per Capita in the World," Food \& Drink, 2013. [Online]. Available: http://www.helgilibrary.com/indicators/fruit-consumption-per-capita/world/.

[5] Marketsandmarkets.com, "Food Blender \& Mixer Market by Type (High Shear, Shaft, Ribbon Mixer, Double Cone, Planetary Mixer, Screw Mixer \& Blender), Application (Bakery, Dairy, Beverage, Confectionery), Technology (Batch, Continuous) \& by Region - Global Trend \& Forecast to 2020," 2015.

[6] Y. Tekmen, "An analysis of the evolution of multifunctional kitchen mixing tools," Middle East Technical University, 2007.

[7] E. Makin, “10 best jug blenders," Independet, 2018. [Online]. Available: http://www.independent.co.uk/extras/indybest/house-garden/kitchen-appliances/best-jugblender-for-smoothies-reviews-ice-soup-glass-a6938586.html.

[8] M. Sen et al., "Analyzing the Mixing Dynamics of an Industrial Batch Bin Blender via Discrete Element Modeling Method," Processes, vol. 5, no. 2, p. 22, 2017.

[9] A. I. Lanas, R. Tanscheit, M. M. Vellasco, and M. A. Pacheco, "Fuzzy and neuro-fuzzy control of a fluid mixer," Computational Intelligence and Applications, 1999. 
Numerical: Jurnal Matematika dan Pendidikan Matematika, Vol. 2 No. 2 Desember 2018, 115-124

Khomarudin Fahuzan, Uke Ralmugiz

[10] M. S. Khan and K. Benkrid, "Design of Liquids Mixing Control System using Fuzzy Time Control Discrete Event Model for Industrial Applications,” vol. II, no. 12, pp. 3-8, 2009.

[11] P. B. Osofisan, "Fuzzy Logic Control of the Syrup Mixing Process in Beverage Production," Leonardo Journal of Sciences, no. 11, pp. 93-108, 2007.

[12] R. K. Karambe and D. H. Gahane, "Automation of Grinder - An Introduction of Fuzzy Logic," Journal of Electrical and Electronics Engineering, vol. 2014, pp. 16-20, 2014.

[13] L. X. Wang, A Course in Furay Systems and Control. New Jersey: Prentice Hall, 1997.

[14] S. K. dan H. Purnomo, Aplikasi Logika Furzy. Yogyakarta: Graha Ilmu, 2010. 
Numerical: Jurnal Matematika dan Pendidikan Matematika, Vol. 2 No. 2 Desember 2018, 115-124

Khomarudin Fahuzan, Uke Ralmugiz

[Halaman ini sengaja dikosongkan] 